\title{
A Five-Year Review of Adverse Cutaneous Drug Reaction in a Tertiary Care Hospital in Yogyakarta, Indonesia
}

\author{
Dyah Ayu Mira Oktarina (D), Maria Sophiati, Erinda Maharani Rambu Moha, Fajar \\ Waskito, Hardyanto Soebono \\ Department of Dermatology and Venereology, Faculty of Medicine, Public Health, and Nursing, \\ Universitas Gadjah Mada/Dr Sardjito Hospital, Yogyakarta, Indonesia
}

\begin{abstract}
Background: The prevalence of adverse drug reactions is likely to increase, and it is associated with increased usage of various drugs. Adverse Cutaneous Drug Reaction (ACDR) is the most frequent adverse drug reaction (30-45\%). In Indonesia, the study on the prevalence of ACDR is still limited. Purpose: This study investigated the prevalence, clinical features, causative agents, and mortality rate of ACDR with a type-IV hypersensitivity reaction among patients attending the Department of Dermatology and Venereology in Dr. Sardjito Hospital, Yogyakarta. Methods: This retrospective study was conducted examining medical records undertaken for five years (2011-2015). Of 68,375 patients medicated in the Department of Dermatology and Venereology, 397 patients were diagnosed as ACDR with a type-IV hypersensitivity reaction. Detailed history, including age, sex, past history, and family history of drug reaction taken by the patient, were obtained. Patch testing was done wherever feasible. Result: Of 68,375 patients, 397 patients were included in ACDR with type-IV hypersensitivity (0.58\%), giving a 5\% of mortality rate. The mean age of the patients was 40.42 years $( \pm 16.30$; range 18 to 89 years). The female to male ratio was 1.1: 1. The Maculopapular rash was the most common ACDR manifestation (50.88\%), followed by Stevens-Johnson Syndrome (13.85\%), Fixed Drug Eruption (12.85\%), and Drug Reaction with Eosinophilia and Systemic Symptoms (10.08\%).The most common causative agents were beta-lactam (16.55\%), NSAIDs (12.18\%), and acetaminophen (8.62\%). Conclusion: Prescription of those drugs should be considered carefully so the incidence of ACDR can be reduced.
\end{abstract}

Keywords: drug eruptions, hypersensitivity, maculopapular exanthema rash, beta lactam.

Correspondence: Dyah Ayu Mira Oktarina, Faculty of Medicine, Public Health, and Nursing, Universitas Gadjah Mada / Dr Sardjito Hospital, Yogyakarta, Indonesia. Email address: d.oktarina@ugm.ac.id, Tel: +6274560700.

Article info | Submited: 5-8-2021, Accepted: 13-9-2021, Published: 30-11-2021

\section{BACKGROUND}

Adverse cutaneous drug reaction (ACDR) is an unpleasant and unanticipated side effect of a medicine on cutaneous that occurs at levels that are widely used in the general population. ${ }^{1}$ Recently, the number of adverse drug reactions is likely to increase, associated with higher life expectancy and increasing access to health services for therapy using various drugs. ${ }^{2}$ Adverse drug reaction occupies the fifth position of deadly diseases. About $30-45 \%$ of adverse drug reaction involves the skin. ${ }^{3}$

Generally, ACDR is classified into two groups: predictable-drug or non-immunologic reaction (TypeA reaction) and unpredictable-drug or immunologic reaction (Type-B reaction). Type-B reaction is caused by immune alteration that results in skin manifestations. There are four hypersensitivity reactions based on Coombs \& Gells, consist of type-I hypersensitivity (Ig-E mediated), type-II hypersensitivity (cytotoxic reaction), type-III hypersensitivity (immune complex-mediated), and type-IV hypersensitivity (delayed-type). ${ }^{4}$ Type-IV hypersensitivity reaction is mediated by T-lymphocyte and manifests as Maculopapular rash (MPR), Drug Reaction with Eosinophilia and Systemic Symptoms (DRESS), Stevens-Johnson Syndrome (SJS), Toxic Epidermal Necrolysis (TEN), Fixed Drug Eruption (FDE), erythroderma, and Acute Generalized Exanthematous Pustulosis (AGEP). ${ }^{2}$ Some researchers find that Maculopapular rash is the most common form of skin drug eruption, whereas others also state that FDR is the most frequent manifestation of ACDR. ${ }^{5}$

Unfortunately, the study of ACDR in Indonesia is limited. This study investigated the prevalence, clinical features, causative agents, and mortality rate of ACDR with type-IV hypersensitivity among patients in the Department of Dermatology and Venereology in Dr. Sardjito Hospital in Yogyakarta, ranged from 20112015. 


\section{METHODS}

This retrospective observational study was undertaken for five years (2011-2015) by recording various medical records in the Department of Dermatology and Venereology in Dr. Sardjito Hospital in Yogyakarta. Detailed history, including age, sex, history, and family history of drug reaction taken by the patient, were recorded. Patch testing was done wherever feasible. Sample used in study were medical records from patient suffering from skin drug-eruption that fulfilled inclusion criteria: diagnosed as ACDR with type-IV hypersensitivity in the Department of Dermatology and Venereology in Dr. Sardjito Hospital, age $\geq 18$ years old, and have complete data, include causative agents, clinical features, age, sex, and history of medication allergy. Patients with incomplete data were excluded from the study. Moreover, data analyzed were prevalence, clinical features, causative agents, and mortality rate of ACDR with type-IV hypersensitivity.

Ethical approval for this study project was obtained from the Ethical Committee of Research, Faculty of Medicine, Public Health, and Nursing

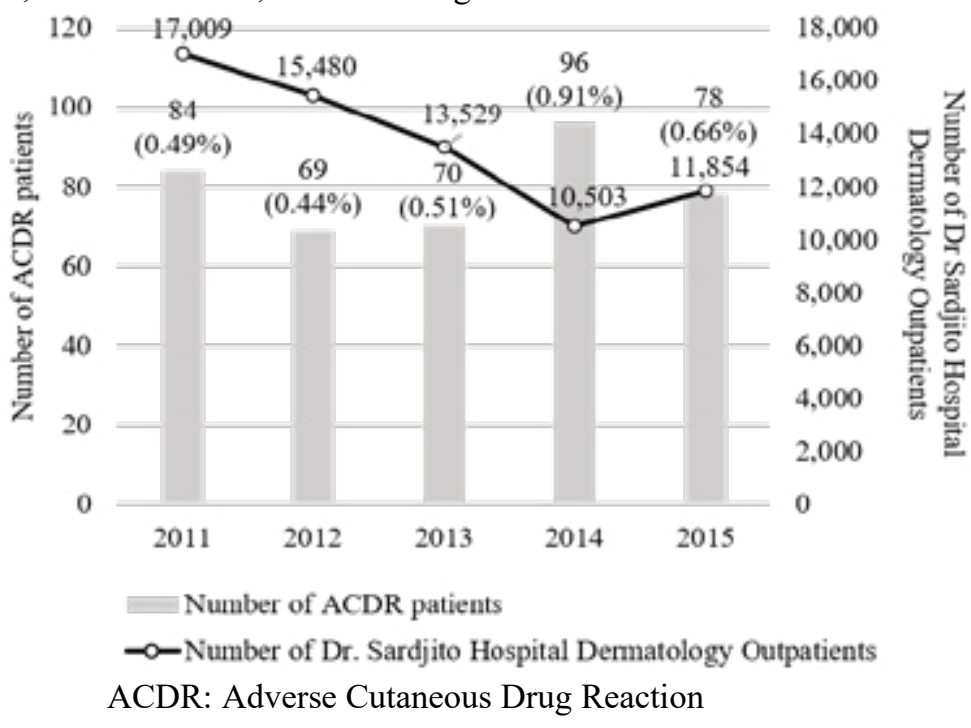

Figure 1. Prevalence of Adverse Cutaneous Drug Reaction (ACDR) with a type-IV hypersensitivity in Dr. Sardjito General Hospital, 2011-2015.

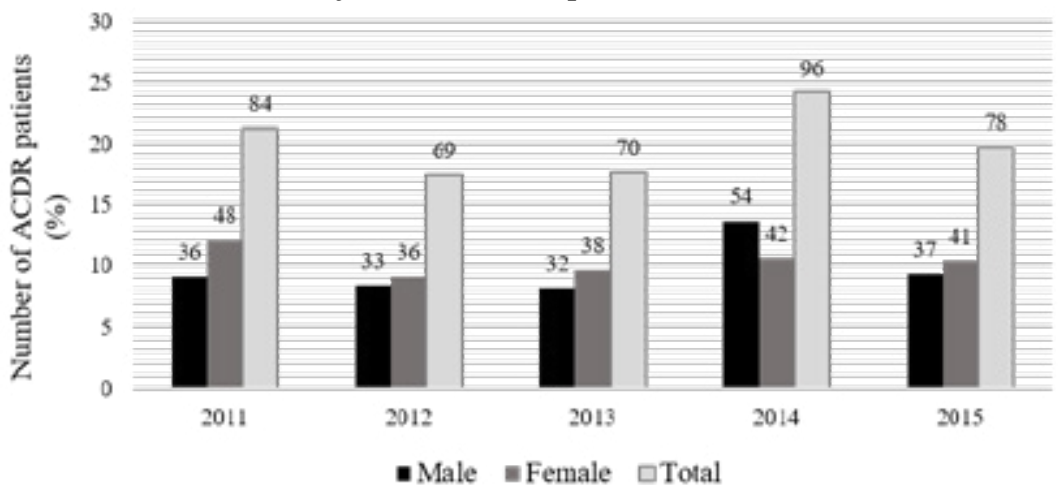

ACDR: Adverse Cutaneous Drug Reaction

Figure 2. Total of Adverse Cutaneous Drug Reaction (ACDR) with type-IV hypersensitivity, comparison between male and female patients. 


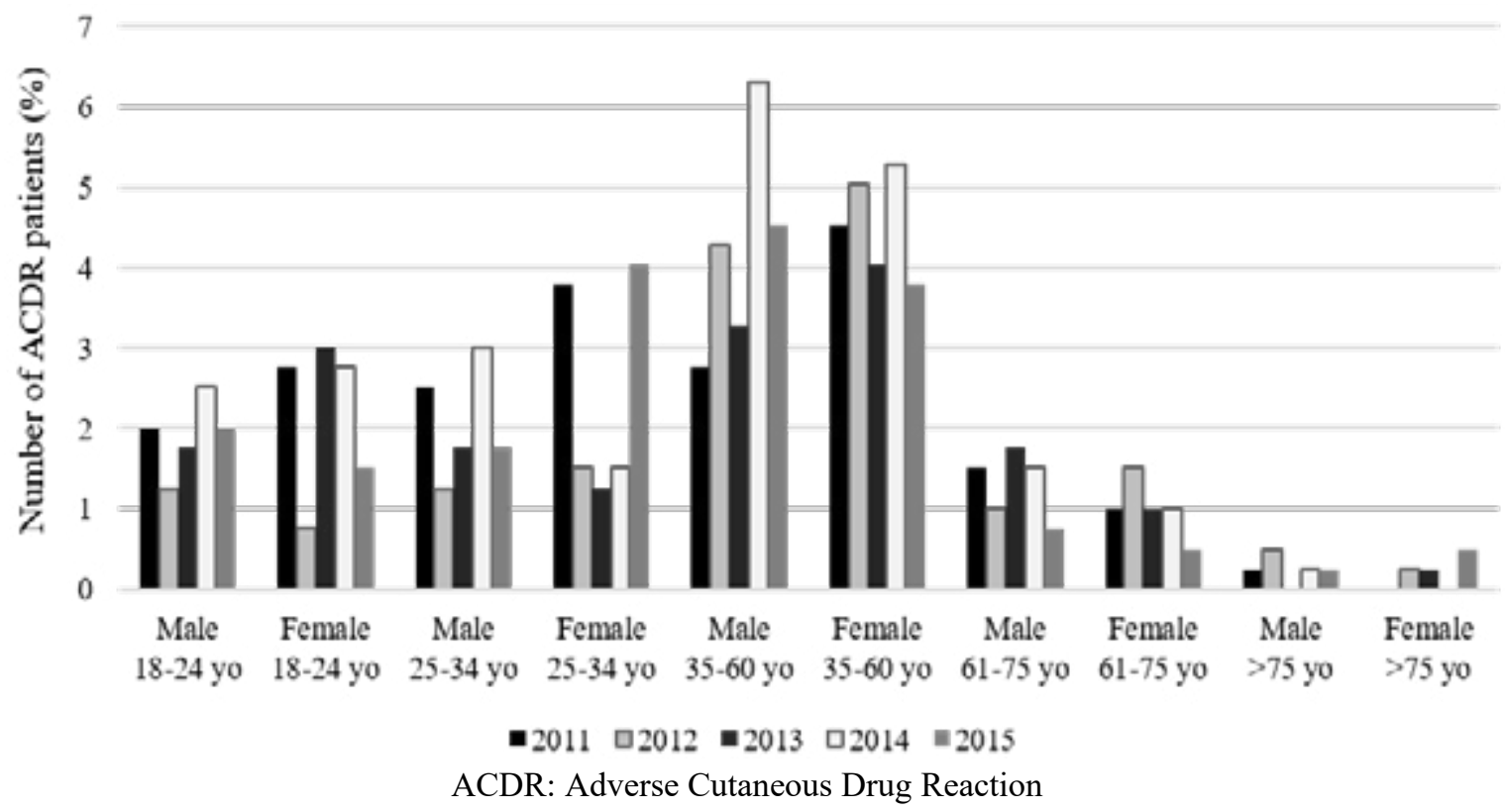

Figure 3. Grouping of Adverse Cutaneous Drug Reaction (ACDR) patients based on age, between male and female patients.

Table 1. Causative agents of Adverse Cutaneous Drug Reaction (ACDR) and clinical manifestations

\begin{tabular}{|c|c|c|c|}
\hline Drug classes & Percentage $(\%)$ & Common drugs implicated & Frequent clinical features $(\%)$ \\
\hline Beta-lactam & 16.55 & $\begin{array}{l}\text { Cefadroxil, Amoxicillin, Cefixime, } \\
\text { Penicillin, Ceftriaxone }\end{array}$ & $\begin{array}{l}\text { MPR (46.28\%), DRESS } \\
(21.49 \%)\end{array}$ \\
\hline NSAID & 12.18 & $\begin{array}{l}\text { Mefenamic Acid, Diclofenac, } \\
\text { Metamizole, Meloxicam, Ibuprofen, } \\
\text { Ketoprofen }\end{array}$ & $\begin{array}{l}\text { MPR }(38.20 \%), \text { FDE } \\
(22.47 \%)\end{array}$ \\
\hline Acetaminophen & 8.62 & - & $\begin{array}{l}\text { MPR }(42.86 \%), \text { FDE } \\
(20.64 \%)\end{array}$ \\
\hline ARV & 6.98 & - & MPR $(74.51 \%)$ \\
\hline Anticonvulsant & 6.29 & Carbamazepine, Phenytoin & $\begin{array}{l}\text { SJS }(36.96 \%), \text { MPR }(23.91 \%) \text {, } \\
\text { SJS-TEN }(15.22 \%) \text {, } \\
\text { TEN }(4.35 \%)\end{array}$ \\
\hline Antituberculous dru & s 5.88 & - & $\begin{array}{l}\text { MPR (69.77\%), DRESS } \\
(16.28 \%)\end{array}$ \\
\hline Cotrimoxazole & 4.51 & - & MPR (57.58\%), SJS (21.21\%) \\
\hline Quinolone & 3.83 & Ciprofloxacin, Levofloxacin & $\begin{array}{l}\text { MPR }(53.57 \%), \text { DRESS } \\
(17.86 \%)\end{array}$ \\
\hline Other antibiotics & 3.69 & $\begin{array}{l}\text { Metronidazole, Clindamycin, } \\
\text { Azithromycin, Doxycycline }\end{array}$ & MPR (55.56\%), SJS (29.63\%) \\
\hline ACE-i \& ARB & 2.60 & Captopril, Valsartan, Irbesartan & MPR (47.37\%), SJS (21.05\%) \\
\hline Allopurinol & 2.33 & - & $\begin{array}{l}\text { SJS (47.06\%), MPR }(29.41 \%), \\
\text { SJS-TEN }(11.77 \%)\end{array}$ \\
\hline Antihistamine & 2.05 & $\begin{array}{l}\text { Chlorpheniramine Maleate, } \\
\text { Ranitidine, Cetirizine }\end{array}$ & MPR (53.33\%), SJS (20.00\%) \\
\hline $\begin{array}{l}\text { Chemotherapy } \\
\text { agents }\end{array}$ & 1.92 & $\begin{array}{l}\text { Docetaxel, Bleomycin, Dacarbazine, } \\
\text { Doxorubicin, Capecitabine, } \\
\text { Carboplatin, Lapatinib, Leukokine, } \\
\text { Methotrexate, Mitomycin, Nilotinib, } \\
\text { Paclitaxel, Vinblastine }\end{array}$ & $\begin{array}{l}\text { MPR }(78.57 \%), \text { FDE } \\
(14.29 \%)\end{array}$ \\
\hline $\mathrm{CCB}$ & 1.50 & Amlodipine & MPR $(72.72 \%)$ \\
\hline Diuretic & 1.50 & Furosemide & $\operatorname{MPR}(60.00 \%)$ \\
\hline \multicolumn{4}{|c|}{$\begin{array}{l}\text { NSAID: Non-steroidal Anti-inflammatory Drugs, ARV: Antiretroviral, ACE-i: Angiotensin Converting } \\
\text { Enzyme Inhibitor, ARB: Angiotensin Receptor Blocker, CCB: Calcium Channel Blocker, MPR: } \\
\text { Maculopapular rash, DRESS: Drug Reaction with Eosinophiliaand Systemic Symptoms, FDE: Fixed Drug } \\
\text { Eruption, SJS: Steven-Johnson Syndrome, TEN: Toxic Epidermal Necrolysis }\end{array}$} \\
\hline
\end{tabular}


Table 2. Distribution of most common drugs in each Adverse Cutaneous Drug Reaction (ACDR) with type-IV hypersensitivity

\begin{tabular}{lll}
\hline \multicolumn{1}{c}{ Clinical Features } & \multicolumn{1}{c}{$\begin{array}{c}\text { Total Cases } \\
\mathrm{n}(\%)\end{array}$} & \multicolumn{1}{c}{ Common drugs implicated } \\
\hline MPR & $202(50.88)$ & Beta-lactam $(15.56 \%)$, ARV $(10.56 \%)$, NSAID (9.44\%) \\
\hline SJS & $55(13.85)$ & Anticonvulsant $(14.5 \%)$ \\
\hline FDE & $51(12.85)$ & NSAID $(27.03 \%)$, Acetaminophen $(17.57 \%)$ \\
\hline DRESS & $40(10.01)$ & Beta-lactam $(32.91 \%)$, NSAID $(18.19 \%)$ \\
\hline Erythroderma & $22(5.54)$ & Beta-lactam $(35.14 \%)$ \\
\hline SJS-TEN & $15(3.78)$ & Anticonvulsant $(19.44 \%)$ \\
\hline AGEP & $8(2.02)$ & Beta-lactam $(26.67 \%)$ \\
\hline TEN & $4(1.01)$ & Anticonvulsant $(22.22 \%)$ \\
\hline
\end{tabular}

MPR: Maculopapular rash, SJS: Steven-Johnson Syndrome, TEN: Toxic Epidermal Necrolysis, FDE: Fixed Drug Eruption, DRESS: Drug Reaction with Eosinophiliaand Systemic Symptoms, ARV: Antiretroviral, NSAID: Nonsteroidal Anti-inflammatory Drugs

From 397 patients, 20 patients (5\%) passed away due to ACDR with hypersensitivity reaction type IV, consist of SJS (9), SJS-TEN (4), TEN (1), FDE (3), MPR (1), and DRESS (2). The most common cause of drug reaction in dead patients were beta-lactam antibiotics (7), NSAID (4), and diuretics (3).

In this study, causative agents were classified into different drug classes. There were 731 drugs suspected as causative agents of ACDR with type-IV hypersensitivity; $80.43 \%$ drugs shown in table 2 , other $19.56 \%$ drugs were causativeagents in a small cases; sulfonamide $(1.37 \%)$, corticosteroid $(1.23 \%)$, antianxiety and antidepressant agents (0.96\%), antifungal (0.96\%), anti-hyperlipidemia (0.96\%), antiplatelet $\quad(0.96 \%)$, anti-psychotic $\quad(0.96 \%)$, mucolytic $(0.96 \%)$, opiates $(0.96 \%)$, antioxidant $(0.68 \%)$, PPI (Proton Pump Inhibitor) (0.68\%), herbal $(0.68 \%)$, anti-diabetic $(0.55 \%)$, antileprosy $(0.55 \%)$, decongestant $(0.55 \%), \quad \beta$-blocker $(0.55 \%)$, antacid $(0.41 \%)$, bronchodilator $(0.41 \%)$, anti-diarrhea $(0.41 \%)$, amiodarone $(0.27 \%)$, antiemetic $(0.27 \%)$, propylthiouracil $(0.27 \%)$, antitussive $(0.27 \%)$, folic acid $(0.27 \%)$, pipemidic acid $(0.27 \%)$, tranexamic acid $(0.27 \%)$, ursodeoxycholic acid $(0.27 \%)$, expectorant $(0.27 \%)$, hepatoprotector $(0.27 \%)$, immune-modulator $(0.27 \%)$, potassium aspartate $(0.27 \%)$, biology agent $(0.14 \%)$, alpha agonist $(0.14 \%)$, anti-spasmodic $(0.14 \%)$, acyclovir $(0.14 \%)$, glycerin $(0.14 \%)$, potassium chloride $(0.14 \%)$, calcium lactat $(0.14 \%)$, sodium bicarbonate $(0.14 \%)$, piracetam $(0.14 \%)$, citicoline $(0.14 \%)$, and vitamin $\mathrm{K}(0.14 \%)$.

\section{DISCUSSION}

The prevalence of Adverse Cutaneous Drug Reaction (ACDR) with type-IV hypersensitivity was $0.58 \%$. A study by Borch et al. in Odense University Hospital in Denmark showed the prevalence rate of ACDR was $1.38 \%{ }^{6}$ The study of Chatterjee et al. in
India reported 739 cases with ACDR from 27,726 patients over one year, yielding a prevalence rate of $2.66 \%{ }^{7}$ Prathap et al. in India reported 71 cases with ACDR from 14,047 patients over one year, giving a prevalence rate of $0.5 \%{ }^{8}$ However, that research included ACDR with all types of hypersensitivity reactions. The study results are influenced by the pharmacogenetic differences on different populations, the freedom to access medicine and healthcare, drugs dosage, use of suspected drugs, and other diseases or comorbidities. $^{9}$

The ratio of females and males was 1.1: 1. Other studies also reported the same results. Adverse drug reaction affects 1.5-1.7 times more in females than males. ${ }^{10} \mathrm{~B}$ o rch et al. also reported the same, the ratio of females to males was 2.3:1. ${ }^{6}$ However, Akalu and Belavadi found the opposite where adverse drug reactions due to antibiotics were observed more in males than females. ${ }^{11}$

Females potentially have a $1.5-1.7$ times higher risk of obtaining unwanted drug reactions than males. ${ }^{10}$ This condition can be caused by differences in pharmacokinetics, immunological factor, epigenetic, and hormonal factor between females and males. Females have more adipose tissue than males, resulting in lower hepatic clearance of drugs that areinfluenced by the enzymatic activity of cytochrome P450. As a result, it will differentiate the drug metabolism between both sexes. ${ }^{12,13}$

In this study, the mean age of patients with ACDR with type-IV hypersensitivity was $40.42 \pm 16.30$ years old. Another study showed the mean age of patients with ACDR was 52 years old. ${ }^{6}$ Older generation poses a higher risk of suffering adverse drug reactions. ${ }^{14}$ Unfortunately, late adulthood and elderly often have several health problems which require many treatments. The decline of visceral organ functional status greatly impacts the pharmacokinetics and pharmacodynamics of the drugs. ${ }^{15}$ 
Based on a study conducted by Alomar, elderly tend to suffer from a type-A Adverse Drug Reaction (ADR), whereas late-adulthood often receives type-B ADR. Type-A ADR is related to the action mechanism of the drugs, dysfunction of the organ, long-term effect of drug administrations, high-risk status of the patients (children, elderly, pregnancy, lactation, cancer, hemodialyzed patients). ${ }^{15}$ Geriatric encounters immunosenescence that attenuates the capability to against antigens. Decrement of visceral organ function, long-term drug administration, and chronic diseases also influence the incidence of type-A ADR. Meanwhile, type-B ADR is related to an immune reaction and drug metabolism, so that often develops in adulthood. ${ }^{16}$

As shown in table 2, beta-lactam antibiotic $(16.55 \%)$ was the most common drug that induced ACDR with type-IV hypersensitivity, followed by NSAID (12.18\%), acetaminophen (8.62\%), antiretroviral drugs $(6.98 \%)$, and anticonvulsant $(6.29 \%)$. Another study showed the same results that beta-lactam was the most common causative agent of ACDR. ${ }^{6}$ Other studies also reported that antibiotics, NSAIDs, and antiepileptic drugs were the most frequent drugs that led to ACDR. ${ }^{7,8}$ Antimicrobial agents and NSAIDs were considered common agents of ACDR. ${ }^{5,17}$ In this study, the most frequent betalactams involved in ACDR were cefadroxil and amoxicillin. NSAIDs that mostly led to ACDRwere mefenamic acid, diclofenac, and metamizole. Carbamazepine and phenytoin were the most common anticonvulsants involved in ACDR. These results are consistent with the study conducted by Qayoom et al. ${ }^{9}$ Singh et al. reported $12 \mathrm{SJS} / \mathrm{TEN}$ patients out of 16 patients, i.e., more than $7.68 \%$ of total patients develop severe reactions. ${ }^{18}$ Hence, carbamazepine and phenytoin in combination cause a more frequent and severe ACDR.

Our study showed that Maculopapular rash was the most common clinical manifestation of ACDR with a type-IV hypersensitivity induced by antibiotics. On the other side, the adverse reaction of anticonvulsant drugs and allopurinol was Stevens-Johnson Syndrome. Amoxicillin is often reported as a cause of maculopapular rashes in many patients. ${ }^{19}$ In another study, penicillin, and quinolones are the most common causative antibiotics for an Adverse Cutaneous Drug Reaction. ${ }^{20}$ Meanwhile, antiepileptic drugs lead to the severe manifestation of ACDR as SJS and TEN. ${ }^{21}$

Beta-lactam class produces a certain clinical feature because it includes hapten drugs that can directly bind to protein lysine groups and then make immunogenic reactions. ${ }^{22}$ After binding to the protein, the drug attach to Antigen Presenting Cell (APC) because APC has Major Histocompatibility Complex (MHC) II. After that, APC activates the Cluster of Differentiation $4^{+}\left(\mathrm{CD}^{+}\right)$. $\mathrm{T}$ lymphocytes release inflammatory cytokines, such as Interleukin- 5, Interleukin-6, Tumor Necrosis Factor (TNF) $\alpha$, and interferon- $\gamma$. Cytokines regulate MHC II on endothelial cells and keratinocytes. These cells activate $\mathrm{CD}^{+}$to produce a clinical feature as a Maculopapular rash or activate perforin and granzyme to produce a clinical feature as SJS, TEN, or FDE. ${ }^{23}$

Furthermore, ACDR is also affected by other factors, including the characteristics of each patient and drug. The chemical structure, dosage form, peak levels of the drugs, and immune response toward the drugs will influence adverse drug reactions. Different drug metabolism will produce different active metabolite substances that create different immune responses. ${ }^{24}$ Different drugs also lead to the different sensitivity of patch test in diagnosing ACDR, such as beta-lactam group antibiotics, which has 39-54\% sensitivity, and NSAID-related FDE has $40-87 \%$ sensitivity. ${ }^{25}$ Hence, the detailed history taking is important to raise suspicious drug that causes ACDR.

There are many factors that affect the prognosis of ACDR, including comorbid conditions and the severity of ACDR. Research conducted by Chatterjee et al. showed that 5 of 739 ACDR patients passed away and manifested as severe ACDR likes SJS and TEN. ${ }^{7}$

As this is a retrospective study, researchers cannot control exposure or outcomes, so it only relies on existing data from medical records. Some samples will be missed if medical records are not complete, so it cannot cover all cases during the study period. In addition, this study only represents samples from one tertiary hospital, thus may not be representative of the larger population.

In conclusion, the prevalence of ACDR with type IV hypersensitivity is relatively low compared to the other developing countries. Maculopapular rash and Stevens-Johnson Syndrome are the most common clinical features of ACDR. Causative agents varied in each patient, dominated by antibiotics, NSAIDs, and anticonvulsants. We recommend for all healthcare providers to recognize common causative agents that often show ACDR, therefore early detection and treatment will prevent complications due to severe ACDR. Close follow-up and monitoring can be considered when healthcare providers give those agents to the patients.

\section{REFERENCES}

1. Beniwal R, Gupta LK, Khare AK, Mittal A, Mehta S, Balai M. Clinical profile and comparison of causality assessment tools in cutaneous adverse 
drug reactions. Indian Dermatol Online J 2019; 10(1):27-33.

2. Gonçalo MM. Cutaneous Adverse Drug Reactions: Contributions to Understand Pathophysiologic Mechanisms Involved in Delayed Reactions (Doctoral dissertation). Universidade de Coimbra Portugal.; 2014.

3. Verma D, Tiwari D, Gupta D, Verma D. Cutaneous adverse drug reactions-a study of clinical patterns, causality, severity and preventability. IOSRJDMS 2014; 13:102-9.

4. Iasella CJ, Johnson HJ, Dunn MA. Adverse drug reactions: type A (Intrinsic) or type B (idiosyncratic). Clin Liver Dis 2017; 21(1):73-87.

5. Sharma R, Dogra D, Dogra N. A study of cutaneous adverse drug reactions at a tertiary center in Jammu, India. Indian Dermatol Online J 2015; 6(3):168-71.

6. Borch JE, Andersen KE, Bindslev-Jensen C. Cutaneous adverse drug reactions seen at a university hospital department of dermatology. Acta Derm Venerol 2006; 86(6):523-7.

7. Chatterjee S, Ghosh AP, Barbhuiya J, Dey SK. Adverse cutaneous drug reactions: A one year survey at a dermatology outpatient clinic of a tertiary care hospital. Indian J Pharmacol 2006; 38(6):429.

8. Prathap P, Elsy M, Ajitha K, Kumar A, George S. Clinical profile of cutaneous adverse drug reactions in a tertiary care centre. IRA-Int J Appl Sci 2016; 3:424-30.

9. Qayoom S, Bisati S, Manzoor S, Sameem F, Khan $\mathrm{K}$. Adverse cutaneous drug reactions - a clinicodemographic study in a tertiary care teaching hospital of the Kashmir Valley, India. Arch Iran Med 2015; 18:228-33.

10. Hendriksen LC, van der Linden PD, LagroJanssen ALM, van den Bemt PMLA, Siiskonen SJ, Teichert M, et al. Sex differences associated with adverse drug reactions resulting in hospital admissions. Biol Sex Differ 2021; 3:12-34.

11. Akalu SD, Belavadi NG. Pattern of adversedrug reactions due to antibiotics in a tertiary care hospital. Int J Basic Clin Pharmacol 2017; 6(8):2027-31.

12. Rademaker M. Do women have more adverse drug reactions?. Am J Clin Dermatol 2001; 2(6):349-51.

13. Mauvais-Jarvis F, Berthold HK, Campesi I, Carrero J-J, Dakal S, Franconi F, et al. Sex and genderbased pharmacological response to drugs. Pharmacol Rev 2021; 73(2):730-62.
14. Dubrall D, Just KS, Schmid M, Stingl JC, Sachs B. Adverse drug reactions in older adults: a retrospective comparativeanalysis of spontaneous reports to the German Federal Institute for Drugs and Medical Devices. BMC Pharmacol Toxicol 2020; $21: 25$.

15. Alomar MJ. Factors affecting the development of adverse drug reactions (Review article). Saudi Pharm J SPJ Off Publ Saudi Pharm Soc 2014; 22(2):83-94.

16. Lavan AH, Gallagher P. Predicting risk of adverse drug reactions in older adults. Ther Adv Drug Saf 2016; 7(1):11-22.

17. Jung J-W, Cho S-H, Kim K-H, Min K-U, Kang H-R. Clinical features of fixed drug eruption at a tertiary hospital in Korea. Allergy Asthma Immunol Res $2014 ; 6(5): 415-20$.

18. Singh PK, Kumar MK, Kumar D, Kumar P. Morphological pattern of cutaneous adverse drug reactions due to antiepileptic drugs in Eastern India. J Clin Diagn Res JCDR 2015; 9(1):WC013.

19. Weisser C, Ben-Shoshan M. Immediate and nonimmediate allergic reactions to amoxicillin present a diagnostic dilemma: a case series. J Med Case Reports 2016; 10(10):1-5.

20. Jung IY, Kim JJ, Lee SJ, Kim J, Seong H, Jeong W, et al. Antibiotic-related adverse drug deactions at a tertiary care hospital in South Korea. BioMed Res Int 2017; 4304973.

21. Park CS, Kang DY, Kang MG, Kim S, YeYM, $\mathrm{Kim} \mathrm{SH}$, et al. Severe cutaneous adverse reactions to antiepileptic drugs: a nationwide registry-based study in Korea. Allergy Asthma Immunol Res 2019; 11(5):709-22.

22. Jeimy S, Ben-Shoshan M, Abrams EM,Ellis AK, Connors L, Wong T. Practical guide for evaluation and management of beta-lactam allergy: position statement from the Canadian Society of Allergy and Clinical Immunology. Allergy Asthma Clin Immunol 2020; 16(1):95.

23. Pichler WJ, Yawalkar N, Britschgi M, Depta J, Strasser I, Schmid S, et al. Cellularand molecular pathophysiology of cutaneous drug reactions. Am J Clin Dermatol 2002; 3(4):229-38.

24. Shamna M, Dilip C, Ajmal M, Linu Mohan P, Shinu C, Jafer CP, et al. A prospective study on adverse drug reactions of antibiotics in a tertiary care hospital. SaudiPharm J SPJ 2014; 22(4):3038.

25. Wibisono Y, Damayanti D. Skin test for cutaneous adverse drug reactions. Berkala Ilmu Kesehatan Kulit dan Kelamin 2020; 32(1):62-9 